\title{
Revalidação do painel sorológico destinado a avaliação de kits para o diagnóstico sorológico do HIV
}

\author{
Revalidation of the positive serological panel intended for the \\ quality control of kits for HIV serological diagnosis
}

\author{
Yasmin Rosa Ribeiro* iD \\ José Roberto \\ Niemeyer de Castro \\ Helena Cristina Balthazar \\ Guedes Borges iD \\ Danielle Copello Vigo ic \\ Danielle Custódio \\ Deslandes Passo iD \\ Marli Melo da Silva iD \\ Gabriella Pires da Silva Macedo ii
}

Instituto Nacional de Controle de Qualidade em Saúde, Fundação Oswaldo Cruz (INCQS/Fiocruz), Rio de Janeiro, RJ, Brasil

\section{* E-mail: yr.ribeiro@hotmail.com}

Recebido: 30 abr 2020 Aprovado: 12 jul 2021

\section{RESUMO}

Introdução: Os kits empregados no diagnóstico do vírus da imunodeficiência humana (HIV) devem cumprir requisitos da $\operatorname{RDC} n^{\circ} 36$, de 26 de agosto de 2015, para registro junto à Agência Nacional de Vigilância Sanitária e da Lei $n^{\circ}$ 6.360, de 23 de setembro de 1976, para comercialização no país. Uma das etapas do registro é a análise prévia laboratorial dos produtos de maior classe de risco (classe IV), realizada pelo Laboratório de Sangue e Hemoderivados (LSH). Na análise dos produtos são utilizados painéis sorológicos constituídos de amostras verdadeiro positivas como principal ferramenta na avaliação de sensibilidade. Objetivo: Revalidar painel sorológico verdadeiro positivo para HIV, destinado à avaliação de kits de diagnóstico in vitro do HIV. Método: Foram realizadas a avaliação retrospectiva e a seleção dos resultados do painel frente aos kits recebidos para análise prévia de janeiro de 2010 a dezembro de 2011 que obtiveram resultado satisfatório. Foi utilizado como critério de revalidação a reatividade das amostras do painel em três ensaios imunoenzimáticos (ELISA), em três ensaios de quimiluminescência (CLIA), em três ensaios imunocromatográficos (testes rápidos) e em três western blot; e reatividade em um ensaio enzimático fluorescente ligado à enzima (ELFA), além do volume igual ou superior a $1 \mathrm{~mL}$. Resultados: No período foram recebidos para análise no LSH 73 kits para diagnóstico in vitro da infecção pelo HIV, sendo 47 (64,4\%) satisfatórios, assim distribuídos: 43,0\% (20/47) ELISA, 34,0\% (16/47) ensaios imunocromatográficos, 13,0\% (06/47) western blot, 2,0\% (01/47) ELFA e $8,0 \%$ (04/47) ensaios de quimiluminescência. Após a avaliação, 77,0\% (34/44) das unidades foram revalidadas, sendo excluídas do painel $23,0 \%$ (10/44), pois não alcançaram os critérios estabelecidos. Conclusões: 0 painel revalidado atualmente é composto por 34 unidades de amostras verdadeiro positivas, com resultados consistentes, aumentando, assim, a confiabilidade e a segurança das análises realizadas e dos testes comercializados no país.

PALAVRAS-CHAVE: HIV; Painel Sorológico; AIDS

\section{ABSTRACT}

Introduction: Kits used in the diagnosis of the human immunodeficiency virus (HIV) must meet the requirements of RDC No. 36, of August 26, 2015 for registration with the National Health Surveillance Agency and Law No. 6.360, of September 231976 for commercialization in the country. One of the registration steps corresponds to the previous laboratory analysis of the products with the highest risk class (class IV), carried out by the Laboratory of Blood and Blood Products (LSH). In the analysis of the products, serological panels consisting of true positive samples are used as the main tool in the sensitivity assessment. Objective: To revalidate a true HIV positive serological panel for the evaluation of in vitro HIV diagnostic kits. Method: A retrospective evaluation and selection of the panel results was performed against the kits that obtained satisfactory results and were received for prior analysis from January 2010 to December 2011. The reactivity of the panel samples in three immunoenzymatic assays (ELISA), in three chemiluminescence assays (CLIA), in three immunochromatographic assays (rapid tests) and in three western blots was used as revalidation criterion; and reactivity in an enzyme-linked fluorescent enzyme assay (ELFA), in addition to a volume equal to or greater than $1 \mathrm{~mL}$. Results: During the period, 73 kits for in vitro diagnosis of HIV 
infection were received for analysis at the LSH, 47 (64.4\%) of which were satisfactory, distributed as follows: $43.0 \%$ (20/47) ELISA, 34.0\% (16/47) immunochromatographic assays, $13.0 \%$ (06/47) western blot, 2.0\% (01/47) ELFA, 8.0\% (04/47) chemiluminescence assays. After the evaluation, $77.0 \%$ (34/44) of the units were revalidated, and $23.0 \%(10 / 44)$ were excluded from the panel, as they did not meet the established criteria. Conclusions: The revalidated panel currently consists of 34 units of true positive samples, with consistent results, thus increasing the reliability and safety of the analyses carried out and of the tests marketed in the country.

KEYWORDS: HIV; Serological Panel; AIDS

\section{INTRODUÇÃO}

A síndrome da imunodeficiência adquirida (AIDS), identificada em 1981, tornou-se um marco na história ${ }^{1}$. Em busca de respostas sobre a doença, se iniciava assim, uma corrida contra o tempo que perdura até nossos dias, na busca da cura dessa síndrome. Em outubro de 1983, no Instituto Pasteur, foi realizado o primeiro isolamento do vírus da imunodeficiência humana (HIV), retirado de linfonodos de pacientes com linfoadenopatia, característica de um estágio inicial da AIDS².

A transmissão do HIV pode ocorrer principalmente por via sexual, por contaminação sanguínea ou por transmissão vertical ${ }^{3}$. A infecção pelo HIV pode ser caracterizada em três fases: fase aguda (nas primeiras semanas de infecção, nas quais há intensa replicação viral), fase persistente (caracterizada pela manutenção dos níveis de TCD4+ e baixa concentração de HIV plasmático) e AIDS (quando ocorre redução significativa de células TCD4+, altos níveis de HIV plasmático e aparecimento de manifestações clínicas características e infecções oportunistas) ${ }^{4}$. Existem dois retrovírus capazes de levar a AIDS, o HIV-1 e o HIV-2, sendo o tipo 2 apresentado em indivíduos que tiveram contato com a população do continente africano ${ }^{5}$.

No Brasil, o diagnóstico da doença em indivíduos com idade acima de dois anos é baseado na detecção de anticorpos, em concordância com a Portaria do Gabinete do Ministro/Ministério da Saúde (GM/MS) $n^{\circ} 59$, de 28 de janeiro de 2003. Para a identificação da infecção pelo HIV em crianças com idade inferior a dois anos, são utilizados testes para quantificação da carga viral do HIV-1, em função da transferência passiva de anticorpos da mãe para o bebê, que pode ocasionar resultados falso positivos nos testes para detecção de anticorpos ${ }^{6}$.

Os testes para detecção de anticorpos anti-HIV podem ser classificados em testes de triagem ou confirmatórios. São considerados de triagem os primeiros testes realizados para identificar possíveis indivíduos infectados pelo HIV, sendo eles: o ensaio imunoenzimático (ELISA), o ensaio enzimático fluorescente ligado à enzima (ELFA), o ensaio de quimioluminescência (CLIA) e o imunocromatográfico (teste rápido), pois apresentam alto grau de sensibilidade. Os confirmatórios são testes ou conjuntos de testes que podem definir o diagnóstico de uma unidade de sangue após um resultado inicial reagente, tais testes possuem alto grau de especificidade, ou seja, correspondem ao percentual de resultados negativos obtidos quando há ausência de determinado marcador na amostra, são eles: o western blot, reação de imunofluorescência indireta (IFI) e a detecção do genoma do vírus HIV'.

De acordo com a Resolução de Diretoria Colegiada (RDC) n 36, de 26 de agosto de 2015, os produtos de diagnóstico de uso in vitro são classificados pela relevância epidemiológica e para fins de regularização junto à Agência Nacional de Vigilância Sanitária (Anvisa), em quatro classes de risco (I, II, II e IV). Os kits para o diagnóstico do HIV pertencem à classe de maior risco (IV) e, de acordo com a legislação vigente, devem ser registrados pela Lei $n^{\circ} 6.360$, de 23 de setembro de 1976, somente produtos registrados na Anvisa podem ser comercializados. Uma das etapas do registro corresponde à análise prévia laboratorial para verificação do desempenho do produto, na qual os parâmetros de sensibilidade e de especificidade devem ser atendidos ${ }^{7,8}$.

Desde 1995, a avaliação prévia desses produtos é realizada pelo Laboratório de Sangue e Hemoderivados (LSH) pertencente ao Instituto Nacional de Controle de Qualidade em Saúde (INCQS), da Fundação Oswaldo Cruz (Fiocruz) ${ }^{8}$.

Na análise prévia dos produtos destinados ao diagnóstico do HIV são utilizados painéis sorológicos constituídos de amostras verdadeiro positivas como principal ferramenta na avaliação da sensibilidade clínica ou diagnóstica, além da utilização de padrões internacionais e painéis internacionais comercialmente disponíveis. 0 painel é um conjunto de unidades de plasma consideradas impróprias para o uso terapêutico, provenientes de serviços de hemoterapia das diversas regiões do país. As unidades de plasma obtidas a partir do fracionamento do sangue total de doadores que apresentaram reatividade para HIV e atenderam aos critérios de validação do LSH, realizadas a partir do ano de 1996, formam o painel sorológico verdadeiro positivo (PSVP) para HIV, atualmente composto por 44 amostras.

Dessa forma, o objetivo desse estudo foi realizar a revalidação do painel do HIV, que é de extrema relevância para manutenção da confiabilidade e segurança dos testes empregados no diagnóstico sorológico, uma vez que anualmente são disponibilizados novos kits no mercado nacional e internacional, com finalidade de atender a demanda da população por testes cada vez mais sensíveis.

\section{MÉTODO}

Com o objetivo de revalidar o painel sorológico positivo para HIV, foram avaliados os resultados das unidades que compõem o painel do HIV utilizadas na avaliação da qualidade dos kits de diagnóstico para essa patologia, que foram encaminhados para análise prévia ao LSH em cumprimento à $\operatorname{RDC} n^{\circ}$ 36/2015 para fins de registro na Anvisa.

Foram considerados para o presente estudo somente os kits que obtiveram laudo satisfatório para os parâmetros de sensibilidade (100,0\%) e especificidade ( $\geq 99,5 \%$ ) no período de janeiro de 2010 a dezembro de 2011, esses parâmetros foram adotados junto à Anvisa. Foi realizado o levantamento dos resultados das amostras que compõem o 
painel sorológico frente às metodologias de ELISA, ensaio imunocromatográfico, western blot, ELFA e CLIA, realizadas no laboratório no período selecionado. Os dados obtidos foram compilados em planilha de resultados no Excel $\circledast$. Nas planilhas dos testes de ELISA, ELFA e CLIA, foram acrescentados os valores da razão, que é obtido através do cálculo entre a densidade óptica (DO) e cut-off (CO, ponto de corte) - (DO/CO) dos testes rápidos e no teste de western blot foi adicionada a reatividade (R) ou não (NR) apresentada no teste.

Para a revalidação do painel do HIV, foi estabelecido como critério a positividade das amostras em três testes ELISA, em três ensaios imunocromatográficos, em três western blot, um ELFA e três CLIA, além de volume igual ou superior a $1 \mathrm{~mL}$ das amostras em estoque ou em rotina laboratorial. Os critérios de revalidação estabelecidos foram baseados nos critérios de validação realizados na confecção do painel, a fim de garantir resultados fidedignos ${ }^{10}$.

Nas metodologias ELISA e CLIA, foram consideradas positivas somente as amostras que apresentaram valor da razão $(\mathrm{DO} / \mathrm{CO}) \geq 1,5$, para maior garantia da reatividade e melhor uniformidade aos resultados ${ }^{10}$.

Foram revalidadas somente as unidades de amostra que cumpriram todos os critérios previamente estabelecidos. As amostras que não atenderam na totalidade os critérios foram excluídas do painel para HIV e segregadas, passando a compor um painel de amostras indeterminadas.

\section{RESULTADOS E DISCUSSÃO}

No período de janeiro 2010 a dezembro de 2011 foram encaminhados para análise prévia no INCQS 73 kits de diagnóstico in vitro do HIV como requisito para o registro de produtos junto à Anvisa, nas metodologias ELISA, teste rápido, western blot, ELFA e CLIA. Após a avaliação laboratorial, $47(64,0 \%)$ produtos foram considerados satisfatórios para os parâmetros de sensibilidade $(100,0 \%)$ e especificidade (>99,5\%) e 26 (36,0\%) foram insatisfatórios. No que diz respeito às metodologias avaliadas, os testes satisfatórios corresponderam a $20(43,0 \%)$ testes ELISA, $16(34,0 \%)$ testes rápidos, seis $(13,0 \%)$ western blot, um (2,0\%) ELFA, e quatro (8,0\%) CLIA (Figura 1).

As avaliações foram realizadas com o objetivo de garantir o desempenho dos produtos disponibilizados no mercado nacional. Os kits com laudo insatisfatório não obtiveram registro na Anvisa e, portanto, não foram incluídos no estudo. No Brasil, a utilização de produtos para o diagnóstico in vitro não registrados, além de ilegal, pode impactar na qualidade e fidelidade dos resultados, o que não pode ocorrer quando se trata da segurança da saúde do usuário ${ }^{10}$.

A avaliação retrospectiva dos resultados, objetivando a revalidação do painel sorológico do HIV, inicialmente composto de 44 amostras verdadeiro positivas, foi realizada frente aos 47 kits avaliados e que obtiveram laudo satisfatório. Os valores da razão (DO/CO) das amostras nos testes ELISA, ELFA e CLIA e a reatividade ou não nos testes imunocromatográficos e western blot foram compilados e comparados em planilha Excel $\circledast$. Com base nos critérios de revalidação estabelecidos, verificamos que oito $(18,0 \%)$ não atenderam a um ou mais critérios. Um total de sete unidades de amostras $(87,0 \%)$ apresentou razão inferior a 1,5 no CLIA, uma $(12,0 \%)$ foi

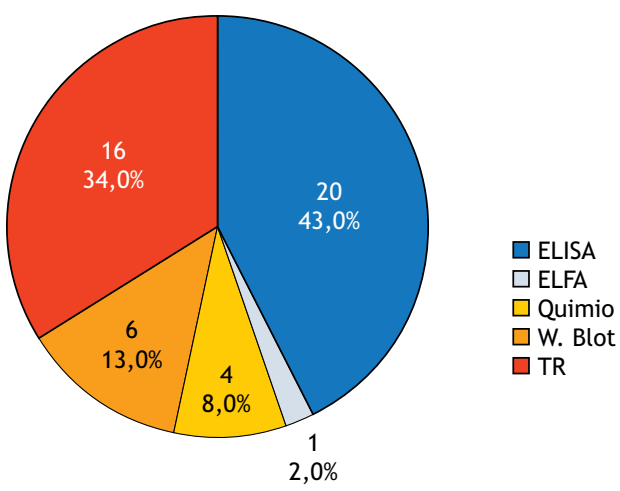

Fonte: Laboratório de Sangue e Hemoderivados, 2020.

Figura 1. Distribuição por metodologia do quantitativo de kits para o diagnóstico do HIV com laudo satisfatório.

não reagente no teste ELFA, e duas $(25,0 \%)$ foram negativas no western blot. Todas as amostras analisadas foram positivas nos três ensaios imunocromatográficos e apresentaram valores de razão (DO/CO) superiores a 1,5 nos três testes ELISA avaliados.

Ressaltamos que as amostras do painel positivo para HIV vêm sendo utilizadas na rotina laboratorial por um período superior a 20 anos, e o longo período de uso poderia justificar a perda ou diminuição da reatividade, principalmente nas unidades com baixos títulos de anticorpos, dificultando assim sua identificação ${ }^{10}$.

Outra hipótese avaliada em relação à reatividade foi o processo de congelamento e descongelamento dos soros, entretanto, segundo estudo de Castejón et al. ${ }^{11}$, o impacto dos múltiplos ciclos de congelamento e descongelamento das amostras de soro estocadas a $-20^{\circ} \mathrm{C}$ não possui efeito significativo na reatividade dos anticorpos específicos, assim não interferindo na reatividade delas ${ }^{11}$.

Para a revalidação, além de cumprir os critérios relacionados à metodologia, as amostras deveriam possuir um volume mínimo de $1 \mathrm{~mL}$ em estoque ou em utilização no $\mathrm{LSH}^{10}$. Verificamos que $26(59,0 \%)$ amostras possuíam volume igual ou inferior a $5 \mathrm{~mL}$. Um total de 16 (36,0\%) possuía volume superior a $5 \mathrm{~mL}$ e 5,0\% (2/44) não estavam disponíveis em estoque. Sendo assim, duas unidades de amostras foram excluídas por não apresentarem volume suficiente para uso.

Do total de amostras positivas do painel HIV, composto inicialmente por 44 validadas, oito $(18,0 \%)$ não apresentaram reatividade em três $(7,0 \%)$ testes CLIA, uma (2,0\%) em ELFA e duas (4,0\%) no western blot e duas (4\%) não possuíam volume suficiente em estoque. Após exclusão das amostras com resultados discordantes ou com volume insuficiente, 34 (77,0\%) foram revalidadas e dez (23,0\%) excluídas por não se adequarem aos critérios estabelecidos para revalidação referentes à metodologia e ao volume (Figura 2).

\section{CONCLUSÕES}

O estudo avaliou o painel sorológico do HIV do LSH, composto por 44 unidades de amostras frente a 47 kits de metodologias e fabricantes diferentes recebidos no período de janeiro de 2010 a dezembro de 2011 no INCQS, com a finalidade de revalidação do painel. 


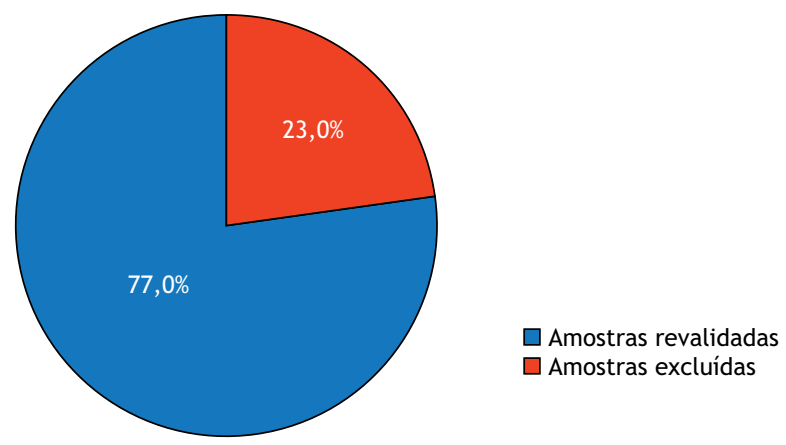

Fonte: Laboratório de Sangue e Hemoderivados, 2020.

Figura 2. Quantitativo de amostras revalidadas e excluídas do painel do HIV do Laboratório de Sangue e Hemoderivados.

O plasma humano utilizado para confecção do painel sorológico possui volume limitado e esgotável, sendo assim, há uma grande necessidade de inserção de novas amostras no painel, sendo o processo dinâmico e randômico. À medida que os novos plasmas atendam às especificações exigidas, serão caracterizados e inseridos ao painel positivo para HIV.

0 estudo demonstrou que grande parte do painel positivo possui baixo volume, sendo 26 (59,0\%) amostras com volume $\leq 5 \mathrm{~mL}, 16$ $(36,0 \%)$ amostras com volume $>5 \mathrm{~mL}$ e duas $(5,0 \%)$ sem volume, ratificando, com isso, a necessidade de recebimento constante de plasmas para cadastro, caracterização e consequente ampliação do número total de amostras verdadeiro positivas para HIV.

O painel verdadeiro positivo para HIV, inicialmente constituído por 44 amostras, após a revalidação, passou a ser composto por 34 unidades. Um total de dez unidades não atendeu aos critérios de revalidação e foi remanejado para o painel de amostras indeterminadas.

A revalidação do painel HIV é de extrema importância, pois reafirma a garantia da confiabilidade e a segurança dos resultados das amostras frente aos kits empregados no diagnóstico in vitro do HIV e, consequentemente, a segurança dos produtos comercializados no país.

\section{REFERÊNCIAS}

1. Goldani LZ. Descoberta do HIV: o reconhecimento. Rev HCPA. 2008;28:205-6.

2. Brito AM, Castilho EA, Szwarcwald CL. AIDS e infecção pelo HIV no Brasil: uma epidemia multifacetada. Rev Soc Bras Med Trop. 2001;34(2):207-17. https: / / doi.org/10.1590/S0037-86822001000200010

3. Santos NSO, Romanos MTV, Wigg MD. Virologia humana. 3a ed. Rio de Janeiro: Guanabara Koogan; 2015.

4. Lopes AC. Tratado de clínica médica. 3a ed. São Paulo: Roca; 2006.

5. Ministério da Saúde (BR). Recomendações para terapia antiretroviral em adultos e adolescentes infectados pelo HIV 2007/2008: documento preliminar. Brasília: Ministério da Saúde; 2008[acesso 30 ago 2018]. Disponível em: www.aids.gov.br

6. Ministério da Saúde (BR). Portaria $N^{\circ} 59$, de 28 de janeiro de 2003. A sub-rede de laboratórios do programa nacional de DST e AIDS, no que concerne ao diagnóstico laboratorial da infecção pelo HIV, será composta por todos os laboratórios, públicos e conveniados ao SUS, que realizam testes sorológicos para a detecção de anticorpos anti-HIV e de antígenos do HIV, organizados hierarquicamente, de acordo com a esfera de gestão do SUS à qual pertencem. Diário Oficia União. 29 jan 2003.
7. Agência Nacional de Vigilância Sanitária - Anvisa. Resolução RDC N ${ }^{\circ} 36$, de 26 de agosto de 2015. Dispõe sobre a classificação de risco, os regimes de controle de cadastro e registro e os requisitos de rotulagem e instruções de uso de produtos para diagnóstico in vitro, inclusive seus instrumentos e dá outras providências. Diário Oficial União. 27 ago 2015.

8. Brasil. Lei $\mathrm{N}^{\circ} 6.360$, de 23 de setembro de 1976. Dispõe sobre a vigilância sanitária a que ficam sujeitos os medicamentos, as drogas, os insumos farmacêuticos e correlatos, cosméticos saneantes e outros produtos, e dá outras providências. Diário Oficial União. 24 set 1976.

9. Chiattone CS, Pereira JPM, Langhi Junior DM, Rugani MA, Souza CA, Saraiva JCP et al. Urgência na introdução do NAT: é fundamental não cometer os erros do passado. Rev Bras Hematol Hemoter. 2008;31(2):113-4. https://doi.org/10.1590/S1516-84842009000200015

10. Ribeiro AS. Confecção de painel sorológico para controle da qualidade de conjuntos de diagnósticos para detecção do antiHIV [monografia]. Rio de Janeiro: Fundação Oswaldo Cruz; 2006.

11. Castejón MJ, Yamashiro R, Oliveira CC, Olivieri JC, Oliveira CAF, Ueda M. Avaliação dos múltiplos ciclos de congelamento e descongelamento na estabilidade dos soros para a detecção de anticorpos anti-HIV. Rev Inst Adolfo Lutz. 2012;71(3)573-81.

\section{Contribuição dos Autores}

Ribeiro YR, Macedo GPS - Aquisição, análise, interpretação dos dados e redação do trabalho. Borges HCBG - Concepção, planejamento (desenho do estudo). Vigo DC, Passo DCD, Silva MM, Castro JRN - Análise e interpretação dos resultados. Todos os autores aprovaram a versão final do trabalho.

Os autores informam não haver qualquer potencial conflito de interesse com pares e instituições, políticos ou financeiros deste estudo.

Licença CC BY-NC atribuição não comercial. Com essa licença é permitido acessar, baixar (download), copiar, imprimir, compartilhar, reutilizar e distribuir os artigos, desde que para uso não comercial e com a citação da fonte, conferindo os devidos créditos de autoria e menção à Visa em Debate. Nesses casos, nenhuma permissão é necessária por parte dos autores ou dos editores. 